\title{
Therapists' Perceptions of the Therapeutic Alliance in 'Mandatory' Therapy with Sex Offenders
}

Jannine Dowling, Suzanne Hodge \& Paul Withers

This is the Author's Original Manuscript of an article published by Taylor \& Francis in The Journal of Sexual Aggression on 25/10/2018, available online:

https://www.tandfonline.com/doi/full/10.1080/13552600.2018.1535139 


\section{Therapists' Perceptions of the Therapeutic Alliance in 'Mandatory' Therapy with Sex Offenders}

Research suggests that the therapeutic alliance (TA) plays an important part in successful therapy. The pan-theoretical concept of the alliance (Bordin, 1979) assumes a client seeks to make change and joins the therapist in a willing journey. However, treatment with sex offenders can entail various levels of coercion. Little is known about the process of the TA in therapy with sex offenders whose therapy could be seen as coerced or mandated. Thus, the aim of this research was to explore therapists' perceptions of the TA with sex offenders whose therapy could be seen as 'mandated' because it was part of their plan for release/rehabilitation. Eleven therapists were interviewed about their experiences and a qualitative thematic analysis elicited five themes: dynamics of forced work, explicit terms of working, persuasive encouragement to engage, connecting with the human element and preservation and protection. Implications for practice are discussed alongside recommendations for future research.

Keywords: Therapeutic alliance; experience; qualitative; sex offender treatment; coercion.

\section{Introduction}

The notion of the therapeutic alliance (TA), also known as the working alliance or helping alliance (Horvath \& Luborsky, 1993) was initially conceptualised by Freud (1912) who felt that a 'proper rapport' was needed for the client to be able to hear interpretations. The term therapeutic alliance was later introduced by Zetzel (1956), to distinguish between transference and alliance and to refer to the concept of a positive client-therapist relationship. There are few clear definitions of what the TA is and what its essential components are (Gelso \& Carter, 1994; Marziali \& Alexander, 1991). The TA can be viewed as the quality of the rapport between the client and therapist which allows therapeutic work to take place (Bordin, 1994; Clarkson, 2003) and how well the client and therapist work together (Horvath, Del Re, Flückiger, \& Symonds, 2011). Bordin (1979) cultivated a pantheoretical concept of 
working alliance, broadening the alliance from its origins in psychoanalytic theory to a concept which could be generalised to all psychotherapies (Arnd-Caddigan, 2012). Although Bordin (1979) used the term 'working alliance', to demonstrate that his theory could work outside of a therapeutic setting, in this research it will be assumed that his working alliance is correspondent to the therapeutic alliance in a therapy setting (Ross, Polascheck, \& Ward, 2008).

The TA is seen as a crucial aspect of the therapy process (Gelso \& Carter, 1985) and it has been well documented that there is a positive relationship between a good alliance and a successful therapy outcome regardless of treatment modality (Horvath et al., 2011; Horvath \& Luborsky, 1993; Horvath \& Symonds, 1991; Martin, Garske, \& Davis, 2000). Metaanalyses have demonstrated the alliance-outcome correlation to be consistent over time and regardless of the potential variables which could moderate the relationship (Martin et al., 2000). This has led to claims that the alliance in therapy is more important than the type of treatment which is used (Martin et al., 2000). Indeed, Bordin (1979) suggested that it is the alliance which is common to all therapy that is the main aid to change in clients (Bordin, 1979, 1994; Horvath \& Luborsky, 1993).

Bordin's $(1979,1994)$ pantheoretical concept suggests that there are three main components of the TA, which are tasks, bonds and goals. The common aspects of the working alliance are defined as 'an agreement on goals, an assignment of task or a series of tasks and the development of bonds' (Bordin, 1979, p. 253). The tasks of the therapy should be seen by both client and therapist as relevant and worthwhile and both need to be committed to the tasks of therapy. The goals should be the target of the intervention and ideally mutually agreed and endorsed. The concept of bonds refers to the positive attachment between therapist and client and includes issues of trust, confidence and acceptance. This would seem to suggest that a good TA would generally require some willingness from the 
recipient of the therapy to make changes and to want to engage in therapy, as Bordin (1979) specifically discusses the alliance as being between a therapist and a person who seeks to make change. Similarly, Horvath \& Luborsky (1993) maintain that a client needs to join the therapist in a willing therapeutic journey, through collaboration and trust, to develop the alliance.

Therapy is usually thought of as a voluntary process (Friedlander, Escudero, \& Heatherington, 2006), where the person who attends therapy is willing and motivated to make a change. However, for people convicted of sex offences there are often external pressures involved in their attendance for therapy or treatment, which could be experienced as coercive. Although it has been said that degrees of pressure occur in all treatment types (Group for the Advancement of Psychiatry, 1994), it is a particular feature for sex offenders (Burdon \& Gallagher, 2002). Cosyns (1999), identified that pressure to comply for sex offenders entering treatment is often external, such as a condition of parole, or a court order. Other recognised factors included pressure from family, internal drives such as guilt and the therapist's use of prestige and power in their interaction with the client (Cosyns, 1999).

Historically sex offenders have been viewed as being in need of treatment or therapy to control their behaviour and accordingly the criminal justice system generally applies pressure to comply in two forms (Burdon \& Gallagher, 2002). The first being through incapacitation (incarceration, supervision etc.) and the second through ensuring some form of treatment to control deviant sexual behaviour and to minimise risk (Kleban \& Jeglic, 2012). In a forensic inpatient setting, therapy for sex offenders is not often strictly mandatory; however, the progress and rehabilitation of the person may often be dependent on their engagement with the therapy process to address their sexual offending issues and therapy may thus have a pronounced de facto element of compulsion. 
The conditions for therapy for sex offenders in forensic settings are markedly different from the assumptions for therapy identified by Bordin (1979) of having a client who seeks to make change and who joins in a willing therapeutic journey (Horvath \& Luborsky, 1993). If treatment is mandated or there is pressure to comply, it may be difficult to achieve true collaboration and partnership; the power differentials may also render the alliance lopsided (Skeem, Louden, Polaschek, \& Camp, 2007).

It would seem that it is difficult to engage sex offenders even when engagement with treatment is an active choice. Langevin (2006) conducted a longitudinal study collating data from the 1960 s to 2000 s, which indicated that only $50 \%$ of sex offenders wanted treatment and only $13 \%$ completed treatment (Langevin, 2006). Furthermore, therapeutic goals when working with clients who are 'mandated', are often predetermined by a third party, rather than a distinct choice of the individual (Friedlander et al., 2006). Sex offenders often have difficulty in trusting professionals (Marshall et al., 2003), so there is an additional barrier to the therapeutic alliance in the sense of having an open trusting relationship. In addition, there are unique ethical and clinical dilemmas presented in work with sex offenders, which may impact on the alliance, such as the material discussed in treatment and the dual role of the therapist in both providing therapy and managing risk and restrictions imposed on the client group (Grady \& Strom-Gottfried, 2011; Skeem et al., 2007). Despite these challenges, research has found that sex offenders have been able to form good working alliances with their therapists (Blasko \& Jeglic, 2014; Polaschek \& Ross, 2010; Tatman \& Love, 2010).

Furthermore, it has been informally suggested that it has still been possible to establish a good TA with sex offenders who have to engage with therapy as part of their rehabilitation plan. Examples of successful treatment which has taken place within other mandated settings have been found (Group for the Advancement of Psychiatry, 1994), and there have even been suggestions that coercion can have a positive role in clinical treatment 
(Cosyns, 1999; O'Hare, 1996). For example, O’Hare (1996) found that court mandated clients often showed willingness to work on their problems with social workers. He recommended that clients could be engaged with involuntary treatment by social workers 'accepting their initial reluctance, avoiding premature confrontation, clarifying the clinician's dual role within the therapeutic-criminal justice matrix, and providing some sense of control and choice in selecting treatment goals and methods' (O'Hare, 1996, p. 421).

Theoretical literature regarding the therapeutic process of working with sex offenders has advocated that the TA is crucial when working with this client group (Marshall et al., 2003; Marshall \& Serran, 2000; Serran, Fernandez, Marshall, \& Mann, 2003; Serran \& Marshall, 2010). The TA is seen as integral to successful treatment and to reducing recidivism (Serran \& Marshall, 2010). Various elements have been identified as being important features which influence the alliance with sex offenders, including empathy and genuineness (see Marshall et al. 2003 for more details). There is relatively little research into how the TA develops in a general therapy setting (Ross, Polascheck, et al., 2008). There is even less research literature looking at how TA is achieved when the client has not overtly chosen to engage with therapy (Group for the Advancement of Psychiatry, 1994). There appears to be little evidence for how therapists develop a TA with clients, where there is not only a mandatory element of treatment, but also where the offences committed might be considered to be abhorrent and distasteful (Kleban \& Jeglic, 2012). Blasko \& Jeglic's (2016) research affirmed that sex offenders felt that they were able to establish strong working alliances with their therapistswith clients who had willingly volunteered to enter therapy. This current research builds on their recommendations of looking at the dynamics of the alliance when therapy has not been something the person has entered into willingly and is seen as having a 'mandatory' element. 
It is, therefore, the aim of this research to explore therapists' perceptions of the TA with sex offenders whose therapy could be seen as mandated, enforced or having a pressure to comply because it was part of their plan for release or rehabilitation and consider how this fits with Bordin's (1979) theoretical concept of the TA. It is hoped that insights from therapists' clinical experiences can further understanding and knowledge in the field about the TA in this underdeveloped area of research. It is hoped that this exploratory work may be a useful starting point to encourage further dialogue around the topic.

\section{Method}

\section{Design}

Thematic analysis allows for summarising of repeated meaningful patterns in data that are important to a phenomenon and associated with a specific research question (Fereday \& Muir-Cochrane, 2008). It is seen as the most appropriate method to investigate a group's conceptualisation of a phenomenon (Joffe, 2012), therefore, qualitative thematic analysis was chosen as the most appropriate methodology.

Semi-structured interviews were used to elicit the views of participants. As the study was concerned with individuals' subjective understandings, an interpretive-constructionist approach was taken. This assumes that reality is socially constructed, and that there are multiple and potentially incongruous realities which exist in relation to any experience (Paterson, Thorne, Canam, \& Jillings, 2001). Thus interpretive-constructionist research involves seeking to understand and interpret the range of understandings that a particular group of participants have of a particular phenomenon (Ashworth, 2008).

\section{Participants}

Potential participants who were invited to take part in the research were qualified therapists who worked in low and medium secure NHS inpatient units in the north of England. To meet the criteria of the research, it was required that participants worked in a one to one setting 
with sex offenders, providing therapy using psychological approaches and techniques. This included clinical psychologists, CBT (cognitive behavioural therapy) therapists, CAT (cognitive analytical therapy) therapists and clinical nurse specialists. Therapists were required to have worked in a one to one setting with sex offenders whose therapy was a necessary part of their treatment plan for release, and needed to have had at least one such client in the last year.

In total, from the four inpatient units which were approached, eleven participants elected to take part; five females and six males. Eight were clinical psychologists and three were clinical nurse specialists. A range of therapeutic approaches were used by the participant sample.

\section{Procedure}

Ethical approval was sought and obtained from Lancaster University's Research Ethics Committee, and from the relevant research and development department for each research site.

Initial contact was made with the management team of four relevant inpatient units to introduce the proposed research. Invitations to take part in the research were then sent on to staff who met the inclusion criteria. Anyone interested in taking part was invited to contact the researcher directly; at which point arrangements were made to conduct the interviews. Face to face interviews were all conducted at the participants' place of work. The opportunity to ask questions was provided at the beginning and the end of the interview. Duration of interviews ranged from 60 to 90 minutes. The interviews were introduced with an overview of the research topic whereby participants were advised that the interview would be flexible and responsive to the things they wished to discuss. An interview schedule was used to provide a guide to the topic areas to cover, however, interviews evolved organically, driven by the particular interests of the participants, with minimal prompts from the researcher. 
Prompt topics on the interview schedule, included items such as: thoughts on the TA within their work with sex offenders [What does it mean to you? How can it be achieved? What are the important factors in doing this? Describe any difficulties], engagement with clients and overall challenges. Interviews were audio-recorded, with consent from the participant, then transcribed verbatim.

\section{Data Analysis}

There is no single standardised way of conducting a thematic analysis (Howitt \& Cramer, 2011), with researchers varying in their approach (Stirling, 2001). However, the current research drew upon the work of Braun and Clarke (2006), following their systematic process for analysing the data. Data analysis was conducted by the first author, and was checked at key stages by the second and third authors. Initially the transcripts were carefully read and reread to ensure familiarity and 'immersion' in the data (Braun \& Clarke, 2006). Secondly, annotations were made in the margin, noting points of interest or significance, to begin an initial coding frame. The data were then coded throughout.

Initial codes from across the data set were then entered into a spreadsheet, supported by relevant extracted quotes. Emerging themes were identified by grouping together initial codes and supporting extracts. To ensure that the themes were accurately grounded in the data, they were systematically checked back against the transcripts. A table was then created to review how the initial codes and themes fitted together. This allowed the data to be inspected as a whole for coherent patterns and to evaluate how the themes fitted together. Finally a map of themes was developed, which allowed visual examination of how well the themes represented the data, (see Figure 1) and facilitated the development of the final themes, which were then defined and named. Table 1 demonstrates the coding frame, from 
which the emerging codes and the final themes were derived. Each theme was supported by multiple extracts from the data.

Insert Figure 1 here

Insert Table 1 here

\section{Quality}

Quality and reliability in qualitative research are less easily defined than in quantitative research. Criteria for quantitative study quality checks cannot be appropriately applied to qualitative research (Yardley, 2008). Instead, issues such as sensitivity to context, rigour and transparency are more appropriate considerations (Yardley, 2000, 2008). A key method of ensuring that these principles are adhered to is to follow and outline a systematic process (Barbour, 2001). This was done by keeping an auditable paper trail and a reflective diary throughout the research process, and through ongoing supervision. In the data analysis phase supervision was used to ensure rigour and transparency of approach and to check the coherence of the first author's interpretations. Furthermore, issues of coherence and transparency have been addressed by using participant quotes extensively throughout the report to support themes and interpretations.

\section{Results}

The analysis elicited five main themes, which were distinct but closely connected and flowed into each other, with levels of overlap throughout.

Theme 1: Dynamics of forced work: 'really truly, it can never be wholly collaborative, because they have to come' 
This theme represents the issues and difficulties which are thrown up when there is a dynamic of doing necessary work with a person. One participant stated 'it's unusual I think to work with sex offenders individually who buy in to what you are doing in the way that you see with non-forensic settings' [PK]. Ambivalence about undertaking therapeutic work presented difficulties for trying to engage with a person: 'you still sometimes are in a room with someone and think you don't even want me to be in this room. That is a challenge' [PE]. Participants raised the issue of what this might mean for therapy, 'so you get like a public agreement, private dissent, always being very aware of that dynamic' [PD].

Participants acknowledged that the pressure to undertake treatment was not just external and from the system but could be from other sources, 'often someone will come truculently and they'll turn up because they want their relationship with their partner and they know that social services are scrutinising them' $[\mathrm{PF}]$; or internally driven, 'people want there to be some kind of change in their life in their social circumstances often around their children' [PE]. Participants also found themselves exerting pressure on clients:

I felt, being quite pushy as a therapist in terms of...overselling the benefits... when you have done this work, you will be more safe to move on, you know the risks, more detail, we will be able to manage your own risks better. When you know really she doesn't want to do that work. So that feels quite difficult at times, feel a bit like a salesman. And of course you don't know, you don't really know what is going to happen. [PD]

Participants noted the odd dynamics of the relationship, particularly the power imbalance: 'power imbalance is quite pronounced despite your best attempts at making it a therapeutic relationship as equal as possible. There's no pretend that it is.' [PC]. There was a sense of being 'the servant to many' [PG], and consideration that the client in the room was not necessarily the one whose interests were being put first, due to the overall purpose of 
treatment and issues of 'political, social control' [PH]. 'You can feel like you have an agenda ... They need to address $\mathrm{x} y$ and $\mathrm{z}^{\prime}[\mathrm{PH}]$. The nature of the work required therapists to have 'our dual role of therapists and risk assessors!' [PI], which meant a conflict of role: 'Sometimes I can be the therapist and the custodian and often the two go back and forward' $[\mathrm{PF}]$.

One of the biggest concerns for therapists was the issue of managing risk and the resulting effect that this could have on the relationship with clients: 'that can cause some problems in the therapeutic relationship obviously...I have had clients that have got quite angry in the sessions about, you know "you think I'm risky, you keep saying I'm risky"'[PA]. The dual role meant that any concerns about risk had to be communicated to others, which impacted on the way of working: 'it can be difficult to maintain a collaborative relationship when the elephant in the room is, what risk does this person present' [PH]. Therapists noted the pressure they were under from their dual role, if the person were to re-offend: 'if he offends will they come back and knock at my door?' [PJ]. This meant that a delicate balancing act was required between therapeutic work and risk management, because of the potential ramifications of re-offending, 'Cos if someone did something unpleasant you would be culpable' [PF].

In summary, it seemed the forced dynamics of treatment meant there was a level of duplicity, because of the ultimate purpose of treatment being 'preventing reoffending': 'you come alongside the client even though really actually you are not alongside the client' [PG].

\section{Theme 2: Explicit terms of working: 'being quite clear from the beginning'}

Despite the seeming duplicity mentioned above, conversely it seemed important to participants to create a semblance of working in an open and explicit way with clients, as much as possible in the circumstances. It seemed to be a crucial element of maintaining the alliance with sex offenders in inpatient settings, for example making explicit the initial 
dynamic of coercion: 'part of making things so explicit about them feeling that they have to come and what that's all about is part of the rapport building' [PE]. Therapists felt that directness was needed to get clients to think about why they were doing work together and also the consequences of not doing work: 'Being honest here, that was important, telling him what's likely to happen if he doesn't do any work...You're not going anywhere if we don't do something about this' [PB]. In addition, participants felt it was important to point out how others perceived their risk and what that meant for their future: 'very upfront and open with them about what their lives are going to be like' [PB]. Being open and direct about dynamics, potential problems and risks seemed to be a key way to establish some rapport and trust: 'My openness and directness I think usually means...that we manage to develop a mutual regard' [PJ].

Being explicit about the dynamics of working together was a way to help give clients some choice and control, in a situation where they do not have much control. Despite the necessity of doing work, therapists attempted to give people choice and control 'so it doesn't feel like a done to process' [PC]. It seemed the purpose of trying to give choice was to 'empower' people to make an 'informed choice', which helped them to engage with the process. One participant stated that 'Ultimately I think if he is going to meaningfully engage he has to be able to choose to do so' $[\mathrm{PH}]$, so giving some control was one way to help therapists overcome potential issues of superficial engagement with treatment.

Interestingly, although participants very much advocated being transparent, one participant noted how the process of giving control to build the alliance was almost coercive in itself, which again emphasises the tension of a level of duplicity: 'increasingly it's sounding very Machiavellian' [PI]. The participant highlighted that it is almost a smokescreen of choice, with the purpose of getting the client on board: 'she is going to let me do what I want to do, at another level I am processing, yeah this is alright, but with my aim of 
engaging you' [PI]. Ultimately, however, the decision to engage was seen as the client's choice: 'they can come and use this space in the way that they want to if they want to or they cannot and they have a choice in that' [PE], but with the understanding that non-engagement would have consequences and that the client was making an informed choice.

\section{Theme 3: Persuasive encouragement to engage: 'I can get people to see that there is a} point to this'

This theme encapsulates the efforts which participants felt they invested in highlighting the benefits of therapy to clients and in facilitating engagement and alliance building. If therapists were able to show the person that there would be something positive for them personally in doing the therapy it made engagement more likely. Participants commonly used goals as motivation to overcome ambivalence and to help clients look to the future and engage with the process: 'so I do a lot of work around setting goals...what do they want out of their life' [PA]. This process also appeared to help the therapist to come alongside the client: 'if you can tap into what someone's hopes and dreams or even what their aims are, to have family or to have intimacy, then you know where you are going and you can unite with them in that goal' [PF].

Not all participants' goals were seen as appropriate and it was noted how often there was negotiation to make goals more 'healthy' and to tie them in with the wider goals of the penal system: 'their goals are going to be very much different from the goals of someone else, our goals for example or the goals of society. But again it's about it's about finding common ground within that' [PG]. Goals needed to be meaningful to the client in terms of what benefit they may reap, but this often appeared to link in with reducing risk of reoffending:

I am asking him not to commit further offences because the benefits to him are going to outweigh the pleasure he gets out of offending. That sounds harsh sometimes but 
that's what I have to do to get the best out of the therapeutic alliance with the man.

$[\mathrm{PB}]$

The alliance was seen as 'crucial' and 'very central to the therapy' [PA], particularly as a tool to help an ambivalent person to undertake therapy meaningfully. Participants highlighted the concerted effort required in building and maintaining the alliance with their clients: 'You have to work much harder with someone who has been told they have to be there' [PB]. Often there was a process of undertaking 'pre-therapy' work, to prepare clients for meaningful work and to facilitate engagement: 'lots and lots of pre-sexual offending work' [PA]. One participant summarised the necessity but difficulty in the process of building the TA: 'it's a challenge. But it's one that is really worthwhile, I think it takes a lot of investment and it can be challenging when people come and they are quite resistant' [PE].

Theme 4: Connecting with the human element - 'seeing the wider person, the person as a whole, not just their behaviour'

Participants spoke about the need get to know the person in the room as part of working on the alliance: 'getting to know someone on a human level, as well as a formal therapy level. I think that's the important part' [PD]. It seemed that some participants used their personality within sessions to engage clients and encourage them to want to be there: 'You have to be able to enthuse the man, and do that through humour, or camaraderie...you have to use your own personality a lot within the session'[PB]. There appeared to be almost a two way process, where participants made themselves amenable to the client: 'he has to feel that you like him and therefore he'll like you' [PB], but also worked on being able to connect with something in the client themselves: 'you can see in that individual that there is something in them that you like' [PG].

Participants spoke about the need to see past the behaviour and sex offender label and to consider the person as a whole: 
Can't think of many more labels in society more stigmatising than being known as a sex offender. So I think being able to work with someone and develop a working relationship that is not based on a label that they have or something they have done. $[\mathrm{PH}]$

One way in which people were able to achieve the connection was to understand the context of the person's behaviour and to have a formulation which gave some explanation for their behaviour: 'So you can totally understand actually knowing more about why they have done what they have done, it's no surprise' [PD].

Participants spoke of a range of therapeutic skills which they felt were particularly needed to cultivate the alliance with sex offenders. Being 'genuine' and being able to foster a sense of trust seemed significant for many participants: 'I am very good at listening and hearing their stories, they feel very able to talk to me and to build up trust with me' [PI]. This could possibly be because they would be asking the person to share intimate and potentially shameful information during the course of therapy: 'People need to trust you with their personal information' $[\mathrm{PC}]$.

\section{Theme 5: Preservation and protection: 'put feelings to one side'}

This final theme illustrates the process of how therapists both preserve and protect the TA with the client, but also how they shield themselves from difficult material that may be discussed. For some participants there was an element of splitting themselves in order to work effectively in the room:

You're sort of sometimes you're a bit like you've got two persona. You've got your normal everyday persona that you work with everybody outside, but when you come into the room you have to put that to one side and be a bit like an actor. [PB] This separation of self seemed to allow the therapist to retain some distance from anything difficult in the room and to have an alliance with the person, regardless of what they 
may personally feel about what the client may have done: 'I feel I have got better at being able to try and make sense of why someone has done something and while keeping very separate the moral judgement' [PK]. This may also be a way of protecting oneself from issues such as vicarious trauma, when dealing with difficult information: 'you're talking about quite emotive material and stuff that you yourself might find kind of, that you want to recoil from, that you might want to protect yourself from' [PD].

If there were difficult feelings experienced most participants felt they would hide this from the client, as exhibiting it could damage the alliance: 'I guess some of the feared emotions for people like shame, disgust. I would try not to show any of those' [PC]. Although some therapists felt that particularly difficult material may 'put some of the therapeutic alliance out of the window' $[\mathrm{PF}]$, others felt that they were genuinely never affected by anything that they heard. This could be seen as de-sensitisation, or could possibly be another form of protecting the alliance they had with the client, as potentially engaging with 'some of the abhorrent things that people do' [PK] could be too overwhelming to then sustain a meaningful relationship.

Having a supportive environment was a way in which participants were able to look after themselves and effectively maintain resilience. This incorporated traditional means of supervision, but also having good colleagues and friends, with whom honest feelings could be aired: 'good friends and people around you who can go to and say he is an absolute little bastard and I cannot stand him. And get it out' [PB]. It seemed important to know that there was support from trusted sources to rely on: 'we supervise each other, probably three people that I know I could phone at any time' [PJ]. Having experienced colleagues to learn from seemed to be one way to learn how to manage the dynamics: 'there is a real benefit to doing this stuff and doing it jointly and having colleagues with much more experience and wisdom' [PK]. Often it was felt that training alone did not prepare people for work with inpatient sex 
offenders and that skills of coping and managing were picked up along the way: 'It's experiential I suppose' [PB].

\section{Discussion}

The overarching aim of the research was to develop a theoretical understanding of therapists' perceptions of the TA with sex offenders, whose therapy could be seen as mandated, enforced or where individuals had some external pressures to comply. Five overarching themes were elicited which were: dynamics of forced work, explicit terms of working, persuasive encouragement to engage, connecting with the human element and preservation and protection.

Participants noted a range of issues arising from the dynamics of forced work which affected the TA. Commonly, it was a challenge to work with people who did not necessarily wish to be there, due to the potential for surface level engagement and a lack of investment in the process. This echoes findings from research by Drapeau et al. (2005) who found that sex offenders needed to want to make changes to genuinely invest in therapy and by Langevin (2006) who found that sex offenders were often ambivalent about treatment. In addition the dual role of therapist and risk manager was difficult at times, because of the potential for ruptures to the alliance when making decisions about someone's risk which could place restrictions on them. The fact that participants had the overarching goal of reducing risk to society meant they were the servant of the system as well as being the servant of the client. This goes somewhat against the 'true collaboration' described by Bordin (1979) and Horvath and Luborsky (1996). Managing this dual role has been noted as being the most difficult but important aspect of working with involuntary clients (Skeem et al., 2007).

However, participants were able to establish alliances with their clients and felt that being very open about the dynamics of coercion and their role in risk management was important to enable the alliance to form. It can be argued that there is an element of duplicity 
in this, as the overall aim is to encourage the client to want to do the work, by allowing some choice and control. This tension between duplicity and genuine collaboration is also present in participants' use of persuasion to encourage the client to see the positives of taking part in therapy, perhaps again reflecting the dual role of therapists in forensic settings in providing client-centred therapy and reducing risk to the public (Prescott \& Levenson, 2010).

To get past issues of ambivalence and to foster investment in the therapy process, a key finding of this research is that participants put a great deal of effort into encouraging the client to see what the benefit was for them from taking part in the therapy. There is some fit here with Bordin's (1979) view that both parties need to be committed to the task of therapy which should be seen as worthwhile and relevant. However there is an additional dimension, unacknowledged in the theory, which is the level of work that must be put in by the therapist to get the client on board with the therapy task. This seems important in engaging clients who may not come to therapy entirely of their own volition. By tying in clients' goals with the over-riding goal of the system to reduce risk and offending, participants were able to present themselves as agents for positive change for the client, hence promoting the TA. A similar approach is recommended by Rooney (2009) who suggests that therapists use reframing to increase the fit between client motivation and outside pressures.

Participants spoke about using a range of techniques to protect the alliance with a client, which included concealing negative emotions, cutting off their feelings, suspending their morals and leaving the 'real' persona at the therapy door. Again this is something which may happen in any therapy setting, in order for therapists to be able to connect with their client (Williams \& Day, 2007), but it seems that the extent to which it occurs with sex offenders in 'mandatory' therapy is greater, perhaps because of the client having perpetrated harm on others. 


\section{Clinical Implications}

The effort participants made to motivate and engage clients described by participants could almost be viewed as pre-therapy work, which seemed particularly important to help clients who were ambivalent about engaging. This fits with the cycle of change model by Prochaska and DiClemente (1982), of not confronting those in the pre-contemplation stage of change, but instead giving information to help clients make a decision about whether they want to make a change. Similarly, using motivational techniques appears particularly helpful with this client group, to roll with any resistance and to help clients consider the benefit of treatment. Using solution focussed approaches is one way to come alongside mandated clients (De Jong \& Berg, 2001), which helps give a sense of choice in the process. Giving clients as much choice as possible is important so there is less of a feeling of therapy being 'done' to them, again increasing the chances of their investment in the therapy process (Rooney, 2009).

To maximise the potential for developing trust with the client, there is a need to be very clear about the ramifications of non-engagement with treatment (Group for the Advancement of Psychiatry, 1994) and also about the dual role of the therapist in managing risk issues (O'Hare, 1996). Again this allows for the client to make some informed choice and to collaborate with the therapist.

It would be helpful for training courses to increase awareness of the different dynamics involved in working with this client group and setting to prepare potential therapists who are new to this kind of work. This may help to reduce the trend reported in this research of participants learning skills more experientially.

\section{Limitations}

This paper focussed on therapists' perceptions of the TA with their clients. The TA itself is a concept rather than a concrete entity and a tangible definition is difficult to 
ascertain. Accordingly, it is possible that each participant would have a different understanding of what the TA is and what it means to them. Participants may have responded differently depending on their interpretation and understanding of the TA.

The status of the researcher as a trainee clinical psychologist may have affected participants' responses within interviews (Hewitt, 2007). Participants may have felt that they needed to demonstrate good practice and may not have explored fully difficulties in the therapeutic alliance. However to try to mitigate this, assurances were given about confidentiality and the aim of the research.

\section{Further research}

It would be interesting to consider the views of sex offenders in relation to the TA to see how these compare with the views of therapists. In particular, a dyad methodology could explore how congruent each party was in their view of the TA. This would highlight whether the effort put in by therapists to achieve the alliance was effective. Such research could also explore how sex offenders view the element of coercion. This would give a better insight into how coercive they see the process and if this indeed does affect how motivated they feel to engage with the treatment. Further research could investigate the whether the degree of motivation of individuals entering treatment impacts on the TA. Quantitative research could also explore if there is any correlation between measures of the TA and therapeutic outcomes for sex offenders in 'mandatory' therapy. This could shed light on how important the alliance is to sex offenders, and whether this impacts on the overall aim of reducing risk in the long term. 


\section{References}

Arnd-Caddigan, M. (2012). The therapeutic alliance: Implications for therapeutic process and therapeutic goals. Journal of Contemporary Psychotherapy, 42(2), 77-85. doi:10.1007/s10879-011-9183-3

Ashworth, P. (2008). Conceptual foundations of qualitative psychology. In J. Smith (Ed.), Qualitative Psychology. A Practical guide to research methods (2nd ed.). London: Sage Publications Ltd.

Bordin, E. S. (1979). The generalizability of the psychoanalytic concept of the working alliance. Psychotherapy: Theory, Research \& Practice, 16(3), 252-260. doi: $10.1037 / \mathrm{h} 0085885$

Bordin, E. S. (1994). Theory and research on the therapeutic working alliance: New directions. In A. O. Horvath \& L. S. Greenberg (Eds.), The working alliance: Theory, research, and practice. (pp. 13-37). Oxford England: John Wiley \& Sons.

Braun, V., \& Clarke, V. (2006). Using thematic analysis in psychology. Qualitative Research in Psychology, 3(2), 77-101. doi:10.1191/1478088706qp063oa

Burdon, W. M., \& Gallagher, C. A. (2002). Coercion and sex offenders - Controlling sexoffending behavior through incapacitation and treatment. Criminal Justice and Behavior, 29(1), 87-109. doi:10.1177/0093854802029001006

Clarkson, P. (2003). The therapeutic relationship (2nd ed.). Philadelphia, PA US: Whurr Publishers.

Cosyns, P. (1999). Treatment of Sexual Abusers in Belgium. Journal of Interpersonal Violence, 14(4), 396-410. doi:10.1177/088626099014004003

De Jong, P., \& Berg, I. K. (2001). Co-Constructing Cooperation with Mandated Clients. Social Work, 46(4), 361-374.

Drapeau, M., Korner, A. C., Granger, L., \& Brunet, L. (2005). What Sex Abusers Say About Their Treatment: Results From a Qualitative Study on Pedophiles in Treatment at a Canadian Penitentiary Clinic. Journal of Child Sexual Abuse: Research, Treatment, \& Program Innovations for Victims, Survivors, \& Offenders, 14(1), 91-115. doi:10.1300/J070v14n01_06

Fereday, J., \& Muir-Cochrane, E. (2008). Demonstrating rigor using thematic analysis: A hybrid approach of inductive and deductive coding and theme development. International journal of qualitative methods, 5(1), 80-92.

Freud, S. (1912). The dynamics of transference. In J. Strachey (Ed.), The standard edition of the complete psychological works of Sigmund Freud (pp. 97-108). London: Horgarth.

Friedlander, M. L., Escudero, V., \& Heatherington, L. (2006). Therapy With Unwilling and Mandated Clients. In M. L. Friedlander, V. Escudero, \& L. Heatherington (Eds.), Therapeutic alliances in couple and family therapy: An empirically informed guide to practice. (pp. 197-210). Washington, DC US: American Psychological Association.

Gelso, C. J., \& Carter, J. A. (1985). The relationship in counseling and psychotherapy: Components, consequences and theoretical antecedents. The Counseling Psychologist, $2,155-243$.

Gelso, C. J., \& Carter, J. A. (1994). Components of the psychotherapy relationship: Their interaction and unfolding during treatment. Journal of Counseling Psychology, 41(3), 296-306. doi:10.1037/0022-0167.41.3.296

Grady, M. D., \& Strom-Gottfried, K. (2011). No easy answers: Ethical challenges working with sex offenders. Clinical Social Work Journal, 39(1), 18-27. doi:10.1007/s10615010-0270-9

Group for the Advancement of Psychiatry. (1994). Forced into treatment: The role of coercion in clinical practice. Washington, DC US: American Psychiatric Association. 
Hewitt, J. (2007). Ethical components of researcher-researched relationships in qualitative interviewing. Qualitative Health Research, 17(8), 1149-1159. doi:10.1177/1049732307308305

Horvath, A. O., Del Re, A. C., Flückiger, C., \& Symonds, D. (2011). Alliance in individual psychotherapy. Psychotherapy, 48(1), 9-16. doi:10.1037/a0022186

Horvath, A. O., \& Luborsky, L. (1993). The role of the therapeutic alliance in psychotherapy. Journal of Consulting and Clinical Psychology, 61(4), 561-573. doi:10.1037/0022006x.61.4.561

Horvath, A. O., \& Symonds, B. D. (1991). Relation between working alliance and outcome in psychotherapy: A meta-analysis. Journal of Counseling Psychology, 38(2), 139-149. doi:10.1037/0022-0167.38.2.139

Howitt, D., \& Cramer, D. (2011). Introduction to Research Methods (3rd ed.). Harlow: Pearson Education Ltd.

Joffe, H. (2012). Thematic Analysis. In David Harper \& Andrew R Thompson (Eds.), Qualitative research methods in mental health and psychotherapy : A guide for students and practitioners (pp. 209-223). Chichester: Chichester : Wiley-Blackwell.

Kleban, H., \& Jeglic, E. (2012). Dispelling the myths: Can psychoeducation change public attitudes towards sex offenders? Journal of Sexual Aggression, 18(2), 179-193. doi:10.1080/13552600.2011.552795

Langevin, R. (2006). Acceptance and Completion of Treatment Among Sex Offenders. International Journal of Offender Therapy and Comparative Criminology, 50(4), 402417. doi:10.1177/0306624x06286870

Marshall, W. L., Fernandez, Y. M., Serran, G. A., Mulloy, R., Thornton, D., Mann, R. E., \& Anderson, D. (2003). Process variables in the treatment of sexual offenders: A review of the relevant literature. Aggression and Violent Behavior, 8(2), 205-234. doi:10.1016/s1359-1789(01)00065-9

Marshall, W. L., \& Serran, G. A. (2000). Improving the effectiveness of sexual offender treatment. Trauma, Violence, \& Abuse, 1(3), 203-222. doi:10.1177/1524838000001003001

Martin, D. J., Garske, J. P., \& Davis, M. K. (2000). Relation of the therapeutic alliance with outcome and other variables: A meta-analytic review. Journal of Consulting and Clinical Psychology, 68(3), 438-450. doi:10.1037/0022-006x.68.3.438

Marziali, E., \& Alexander, L. (1991). The power of the therapeutic relationship. American Journal of Orthopsychiatry, 61(3), 383-391. doi:10.1037/h0079268

McAdams, D. (1999). Personal narratives and the life story. In L. A. Pervin \& O. P. John (Eds.), Handbook of personality: Theory and research (2nd ed.). (pp. 478-500). New York, NY US: Guilford Press.

O'Hare, T. (1996). Court-Ordered versus Voluntary Clients: Problem Differences and Readiness for Change. Social Work, 41(4), 417-422. doi:10.1093/sw/41.4.417

Paterson, B. L., Thorne, S. E., Canam, C., \& Jillings, C. (2001). Meta-study of qualitative health research: A practical guide to meta-analysis and meta-synthesis. Thousand Oaks, CA: Sage.

Prescott, D. S., \& Levenson, J. S. (2010). Sex offender treatment is not punishment. Journal of Sexual Aggression, 16(3), 275-285. doi:10.1080/13552600.2010.483819

Prochaska, J. O., \& DiClemente, C. C. (1982). Transtheoretical therapy: Toward a more integrative model of change. Psychotherapy: Theory, Research \& Practice, 19(3), 276-288. doi:10.1037/h0088437

Rooney, R. H. (2009). Strategies for work with involuntary clients (2nd ed.). New York: Columbia University Press. 
Ross, E. C., Polascheck, D. L. L., \& Ward, T. (2008). The therapeutic alliance: A theoretical revision for offender rehabilitation. Aggression and Violent Behavior, 13(6), 462-480. doi:10.1016/j.avb.2008.07.003

Ross, E. C., Polaschek, D. L. L., \& Ward, T. (2008). The therapeutic alliance: A theoretical revision for offender rehabilitation. Aggression and Violent Behavior, 13(6), 462-480. doi:http://dx.doi.org/10.1016/j.avb.2008.07.003

Serran, G. A., Fernandez, Y., Marshall, W. L., \& Mann, R. E. (2003). Process issues in treatment: Application to sexual offender programs. Professional Psychology: Research and Practice, 34(4), 368-374. doi:10.1037/0735-7028.34.4.368

Serran, G. A., \& Marshall, W. L. (2010). Therapeutic process in the treatment of sexual offenders: A review article. The British Journal of Forensic Practice, 12(3), 4-16. doi:10.5042/bjfp.2010.0421

Skeem, J. L., Louden, J. E., Polaschek, D., \& Camp, J. (2007). Assessing Relationship Quality in Mandated Community Treatment. Psychological Assessment, 19(4), 397410. doi:10.1037/1040-3590.19.4.397

Stirling, J. (2001). Thematic networks: An analytic tool for qualitative research. Qualitative Research, 1(3), 385-405. doi:10.1177/146879410100100307

Williams, L., \& Day, A. (2007). Strategies for Dealing with Clients We Dislike. The American Journal of Family Therapy, 35(1), 83-92. doi:10.1080/01926180600550494

Yardley, L. (2000). Dilemmas in qualitative health research. Psychology \& Health, 15(2), 215-228. doi:10.1080/08870440008400302

Yardley, L. (2008). Demonstrating Validity in Qualitative Psychology. In J. A. Smith (Ed.), Qualitative psychology: A practical guide to research methods. (pp. 235-251). Thousand Oaks, CA US: Sage Publications, Inc.

Zetzel, E. (1956). Current concepts of the transference. International Journal of PsychoAnalysis, 39, 369-376. 
Table 1

Coding frame for emerging and final themes

\begin{tabular}{|c|c|c|}
\hline Initial Codes & Emerging Themes & Final Themes \\
\hline $\begin{array}{l}\text { Ambivalence with engaging } \\
\text { Ambivalence for treatment } \\
\text { Change in motivation over time } \\
\text { Client not wanting to be there } \\
\text { No desire to be there } \\
\text { Superficial engagement } \\
\text { Not wanting to engage } \\
\text { Challenge of client not wanting to be there }\end{array}$ & Ambivalence & \\
\hline $\begin{array}{l}\text { Balance of doing work for greater good } \\
\text { bring coercion into the open } \\
\text { coercion } \\
\text { coercive collaboration } \\
\text { compulsory attendance } \\
\text { Degrees of Choice } \\
\text { dilemma of necessary work } \\
\text { Don't want to talk about offence } \\
\text { external pressure } \\
\text { forced alliance } \\
\text { forced collaboration } \\
\text { Having to have certain conversations } \\
\text { internal pressure } \\
\text { pressure to attend } \\
\text { resistance } \\
\text { Validation of coercive element } \\
\text { assessing motivation } \\
\text { assessing motivation } \\
\text { Hidden agenda } \\
\text { Necessity to engage } \\
\text { overselling benefits } \\
\text { manipulation through relationship } \\
\text { necessary attendance } \\
\text { is it worth it? }\end{array}$ & Levels of coercion & $\begin{array}{c}\text { Dynamics of forced } \\
\text { work }\end{array}$ \\
\hline $\begin{array}{l}\text { acknowledge difficulties } \\
\text { Clarity of role } \\
\text { Different kind of alliance } \\
\text { power of role } \\
\text { conflict role } \\
\text { dual role } \\
\text { power imbalance } \\
\text { being aware of power dynamic } \\
\text { Doing necessary work }\end{array}$ & $\begin{array}{l}\text { Dealing with power and } \\
\text { role }\end{array}$ & \\
\hline $\begin{array}{l}\text { highlighting risk to client } \\
\text { balance of risk } \\
\text { balancing risk with alliance } \\
\text { client understanding of their offence } \\
\text { concern about risk } \\
\text { honesty about risk } \\
\text { Lack of engagement equals risk } \\
\text { Law } \\
\text { managing risk } \\
\text { Preventing/reducing reoffending } \\
\text { risk affecting relationship } \\
\text { understanding client perspective to manage } \\
\text { risk } \\
\text { Understanding offence } \\
\text { Understanding risk } \\
\text { client understanding risk decisions } \\
\text { Time pressure to assess risk } \\
\text { Info sharing rupturing alliance } \\
\text { communicating risk rupturing alliance } \\
\text { Pressure } \\
\text { Providing reports }\end{array}$ & Managing Risk & \\
\hline $\begin{array}{l}\text { Clarity of process } \\
\text { clear boundaries }\end{array}$ & & \\
\hline
\end{tabular}


Clear expectations

honesty about information sharing

honesty re: expectations

Transparency

honest and upfront

importance of trust

making things explicit

Open \& honest

Transparent about role

transparent from beginning

transparent about risk concerns

Letting people know what information you

have about them

Explicit terms of

Importance of boundaries

working

Tackling issues head on

Clarity on confidentiality

balance of choice

choice in therapy

choice to engage

Collaborative working

Giving Choice

Giving choice and control

giving choice and control

allowing options

informed choice

giving control in controlled environment

benefit of doing work

benefit of treatment

benefit to client

collaborative goals

conflicting goals

consequence of non-engagement

Establishing goals

extracting goals

Focus on moving person on

highlighting benefits and positive

outcomes

Benefit of therapy to client

improved future through therapy

joint goals

long term benefit

motivation

Motivational work

purpose of treatment

see the benefit

showing benefits

weighing up the benefit

who is treatment for

frame compulsion as opportunity

Impact of losses from offending

Effectiveness of treatment

\section{Persuasive \\ encouragement to \\ engage}

agreed goals

comparing perspectives

explicit goals and aims

goals in relation to risk

goals to benefit client

Goals to improve clients life

Goals as motivation

Long term goals

match goals of service and client

motivation to change

Society's goals

goal setting as motivation

motivation through goals

wanting something at end of therapy

Persuasion

preparation work

preparing for offence focussed work

preparing for therapy

working hard at alliance

importance of relationship

Therapeutic alliance vital

develop alliance

Working hard at alliance

using coercion to build alliance

give responsibility to client 


\begin{tabular}{|c|c|c|}
\hline $\begin{array}{l}\text { Preparing for difficult conversations } \\
\text { building trust } \\
\text { Gaining trust } \\
\text { Importance of alliance } \\
\text { importance of trust } \\
\text { need to be trusted } \\
\text { Need alliance to get real change not } \\
\text { superficial engagement }\end{array}$ & & \\
\hline $\begin{array}{l}\text { seeing the person } \\
\text { connecting with person } \\
\text { finding something to like } \\
\text { finding something to work on } \\
\text { focus on individual } \\
\text { hearing client perspective } \\
\text { seeing more than the sex offender } \\
\text { seeing person as a whole } \\
\text { separate person from offence }\end{array}$ & $\begin{array}{l}\text { Connecting with the } \\
\text { person not offence }\end{array}$ & \multirow{6}{*}{$\begin{array}{c}\text { Connecting with the } \\
\text { human element }\end{array}$} \\
\hline $\begin{array}{l}\text { clients expectations } \\
\text { seeing clients perspective } \\
\text { understanding person } \\
\text { understanding persons background } \\
\text { understand people } \\
\text { Understanding to engage }\end{array}$ & Understanding the person & \\
\hline $\begin{array}{l}\text { being an ally } \\
\text { being liked } \\
\text { being personable } \\
\text { Building relationship } \\
\text { human connection } \\
\text { human contact } \\
\text { human exchange } \\
\text { humour } \\
\text { positivity } \\
\text { Sharing self } \\
\text { Showing interest } \\
\text { using personality } \\
\text { being human }\end{array}$ & using personality & \\
\hline $\begin{array}{l}\text { being genuine } \\
\text { Clients judging genuineness } \\
\text { demonstrate genuine interest } \\
\text { genuine interest } \\
\text { Need to be genuine } \\
\text { not judging person }\end{array}$ & Being genuine & \\
\hline $\begin{array}{l}\text { amend approach to foster relationship } \\
\text { fit approach with person } \\
\text { flexibility } \\
\text { Flexibility in approach } \\
\text { flexibility in assessment } \\
\text { flexible working } \\
\text { flexibility in sessions }\end{array}$ & Flexibility & \\
\hline $\begin{array}{l}\text { reassurance } \\
\text { approachable } \\
\text { Being creative } \\
\text { belief in change } \\
\text { building skills } \\
\text { compassion } \\
\text { Encouraging engagement } \\
\text { give hope } \\
\text { good people skills } \\
\text { joint work } \\
\text { non- judgemental } \\
\text { not judging } \\
\text { not shaming } \\
\text { open discussion } \\
\text { positive regard } \\
\text { positive reinforcement } \\
\text { praise } \\
\text { Reassurance and support } \\
\text { recognising positives }\end{array}$ & Key therapeutic skills & \\
\hline
\end{tabular}




\begin{tabular}{|c|c|c|}
\hline $\begin{array}{l}\text { Resilient therapist } \\
\text { sitting with difficult material } \\
\text { therapist skills } \\
\text { trusting relationship } \\
\text { understanding }\end{array}$ & & \\
\hline $\begin{array}{l}\text { hiding true feelings } \\
\text { sharing self } \\
\text { split self } \\
\text { leave things at work } \\
\text { suspending morals } \\
\text { cut off emotion } \\
\text { Stand back }\end{array}$ & split self & \multirow{5}{*}{$\begin{array}{c}\text { Preservation and } \\
\text { Protection }\end{array}$} \\
\hline $\begin{array}{l}\text { challenge of what emotion to share } \\
\text { difficult material } \\
\text { hide shame disgust } \\
\text { negative emotion affect TA } \\
\text { not show disgust } \\
\text { staying neutral }\end{array}$ & Hiding negative reactions & \\
\hline $\begin{array}{l}\text { use relationship to encourage attendance } \\
\text { boundaries } \\
\text { de-sensitisation to material } \\
\text { not using self in same way } \\
\text { protecting self in room } \\
\text { balance of boundary and engagement }\end{array}$ & Use of self in room & \\
\hline $\begin{array}{l}\text { importance of supervision and support } \\
\text { Getting support } \\
\text { support from others } \\
\text { Team support } \\
\text { honesty about difficulties } \\
\text { reflection on difficulties }\end{array}$ & Support & \\
\hline $\begin{array}{l}\text { finding own way of learning } \\
\text { finding own way } \\
\text { learn with experience } \\
\text { Need MI } \\
\text { training not specific re: coercion } \\
\text { Learning from others doing the job }\end{array}$ & Training & \\
\hline
\end{tabular}




\section{Figure 1}

Map of themes

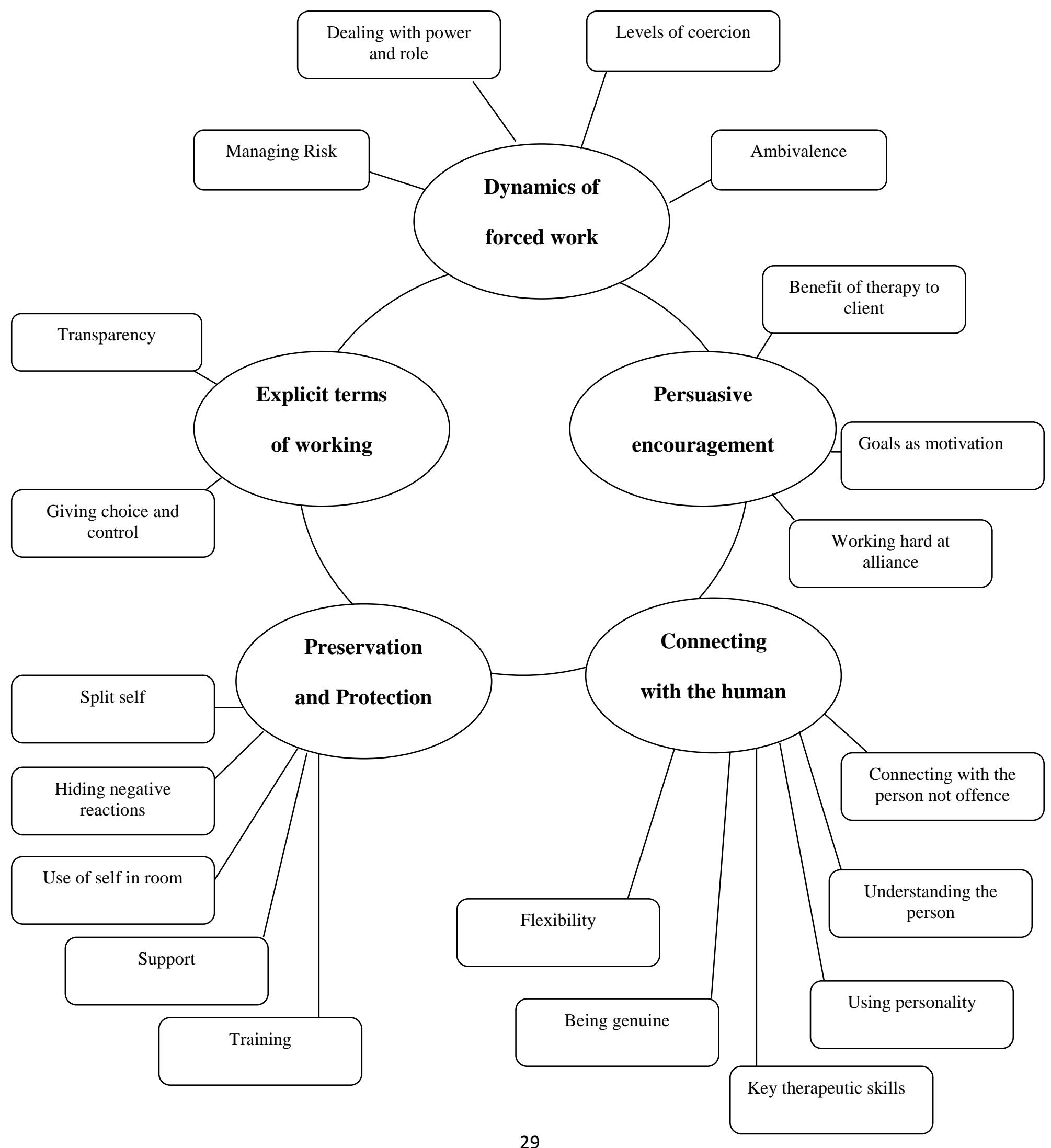


